Sastré Employee of: Novartis Farmacéutica Spain, Pedro Plazuelo-Ramos: None declared, Jordi Gratacos-Masmitja Grant/research support from: Abbvie, BMS, Lilly, MSD, Novartis, Pfizer, Roche, and UCB.

DOI: 10.1136/annrheumdis-2021-eular.2537

\section{POS0993 THE IMPORTANCE OF PHYSICAL ACTIVITY IN RELATION TO BEING OVERWEIGHT/OBESE WITH AXIAL SPONDYLOARTHRITIS. RESULTS FROM THE SPANISH ATLAS}

M. Garrido-Cumbrera ${ }^{1}$, E. Collantes-Estevez ${ }^{2}$, V. Navarro-Compán ${ }^{3}$, P. ZarcoMontejo $^{4}$, J. Correa-Fernández ${ }^{1}$, C. Sastré ${ }^{5}$, P. Plazuelo-Ramos ${ }^{6}$, J. GratacosMasmitja ${ }^{7}$ on behalf of Atlas working group. ${ }^{1}$ Universidad de Sevilla, Health \& Territory Research (HTR), Seville, Spain; ${ }^{2}$ Reina Sofia University Hospital, Rheumatology Department, Cordova, Spain; ${ }^{3}$ Hospital Universitario La Paz, IdiPaz, Madrid, Spain; ${ }^{4}$ Hospital Universitario Fundación Alcorcón, Rheumatology Department, Madrid, Spain; ${ }^{5}$ Novartis Farmacéutica Spain, Immunology, Hepatology and Dermatology, Barcelona, Spain; ${ }^{6}$ Spanish Federation of Spondyloarthritis Associations (CEADE), Presidency, Madrid, Spain; ${ }^{7}$ Hospital Universitaria Parc Taulí, Rheumatology Department, Barcelona, Spain

Background: Evidence on the negative effects of being overweight/obese on the health outcomes of patients with axial spondyloarthritis (axSpA) is increasing. Objectives: This study aimed to identify associations between Body Mass Index (BMI) categories and disease activity, functioning, quality of life, and mental health in a large sample of axSpA patients.

Methods: In 2016, a sample of 680 unselected patients with axSpA participated in the Atlas of Axial Spondyloarthritis in Spain through an online survey. The sample was divided in two groups: 1) Patients with a BMI of 18.5 to $<25 \mathrm{Kg} / \mathrm{m} 2$ (normal weight), and 2) Patients with a BMI of $\geq 25 \mathrm{Kg} / \mathrm{m} 2$ (overweight/obesity), excluding the underweight category (BMI $<18.5 \mathrm{Kg} / \mathrm{m} 2$ ). The Mann-Whitney and Pearson's chi-square tests were used to analyse possible relationships between independent sociodemographic characteristics, employment, lifestyle, patient-reported outcomes, and comorbidity variables with those who are overweight/ obese. Univariate and multivariate binary logistic regression was used to determine the association of the possible factors with those who are overweight/obese. Results: Of the 663 patients analysed, the mean age was 45.9 years, $51.4 \%$ were female, $37.0 \%$ had a university degree, and $72.5 \%$ were married. The prevalence of overweight/obese patients was $53.4 \%$ compared to $46.6 \%$ who were of a normal weight. The patients with the highest prevalence of being overweight/obese were older (49.3 vs $42.0, p<0.001)$, with no university education $(59.8 \%$ vs $42.4 \%$ of university, $p<0.001)$, often widowers $(75.0 \%$ vs $30.8 \%$ of single people, $p<0.001)$, and reported membership of patient organisations $(61.7 \%$ vs $46.6 \%, p<0.001)$. With respect to patients of normal weight, those who were overweight/obese presented greater spinal stiffness $(8.2$ vs $6.6, p<0.001)$ and a longer diagnostic delay $(9.2$ vs $7.8, p=0.005)$. In addition, patients who were overweight/obese were more likely physically inactive $(63.7 \%$ vs $36.3 \%, p=0.007)$. In the multivariable binary logistic regression analysis, the qualitative factors associated with the presence of being overweight/obese were physical inactivity $(\mathrm{OR}=2.40)$ and males $(\mathrm{OR}=1.81)$, while the quantitative factor most associated with the presence of being overweight/ obese were greater spinal stiffness $(B=0.121)$ and older in age $(B=0.052)$ (Table 1).

Table 1. Logistic regression to analyses factor associated with being overweight/obese $(\mathrm{N}=469)$

\begin{tabular}{lllll}
\hline & \multicolumn{2}{l}{$\begin{array}{l}\text { Univariate logistic } \\
\text { analysis }\end{array}$} & \multicolumn{2}{l}{$\begin{array}{l}\text { Multivariate logistic } \\
\text { analysis }\end{array}$} \\
\cline { 2 - 5 } & OR & p-value ${ }^{1}$ & OR & p-value $^{1}$ \\
\hline $\begin{array}{l}\text { Qualitative factors } \\
\text { Gender. Male }\end{array}$ & 2.376 & $<0.001$ & 1.811 & $\mathbf{0 . 0 0 5}$ \\
Educational level. No university & 2.018 & $<0.001$ & 1.188 & 0.422 \\
Marital Status. Widowed & 2.647 & 0.235 & NA & NA \\
Member of PAGs. Yes & 1.851 & $<0.001$ & 1.095 & 0.680 \\
Employment. Retired / early retirement & 4.414 & $<0.001$ & 1.732 & 0.195 \\
Physical activity. No & 1.703 & $\mathbf{0 . 0 0 7}$ & 2.400 & $\mathbf{0 . 0 3 8}$ \\
Quantitative factors & $\mathrm{B}$ & $\mathbf{p}$-value & $\mathbf{B}$ & $\mathbf{p}$ \\
Age & 0.070 & $<0.001$ & 0.052 & $<0.001$ \\
Spinal Stiffness (3-12) & 0.220 & $<0.001$ & 0.121 & $\mathbf{0 . 0 0 4}$ \\
Diagnostic Delay & 0.024 & $\mathbf{0 . 0 3 5}$ & 0.008 & 0.568 \\
\hline
\end{tabular}

${ }^{1} \mathrm{p}$-value for test $\mathrm{H}_{0}: \mathrm{OR}=1^{2} \mathrm{p}$-value for test $\mathrm{H}_{0}: \mathrm{B}=0$.

Conclusion: Being overweight/obese is a common comorbidity among patients with axSpA. The lack of physical activity, male gender, higher spinal stiffness, and older age increase the probability of prevalence of being overweight/obese. Physicians should encourage physical activity in patients with axSpA, especially among men and older people to prevent the factors of being overweight/obese. Acknowledgements: This study was supported by Novartis Spain. The authors would like to thank all patients who participated in the study.
Disclosure of Interests: Marco Garrido-Cumbrera: None declared, Eduardo Collantes-Estevez Grant/research support from: Abbvie, BMS, Lilly, MSD, Novartis, Pfizer, Roche, and UCB, Victoria Navarro-Compán Grant/research support from: Abbvie, BMS, Lilly, MSD, Novartis, Pfizer, Roche, and UCB, Pedro Zarco-Montejo: None declared, José Correa-Fernández: None declared, Carlos Sastré Employee of: Novartis Farmacéutica Spain, Pedro Plazuelo-Ramos: None declared, Jordi Gratacos-Masmitja Grant/research support from: Abbvie, BMS, Lilly, MSD, Novartis, Pfizer, Roche, and UCB.

DOI: 10.1136/annrheumdis-2021-eular.2545

\section{POS0994 NON-RHEUMATOLOGISTS FIND IT DIFFICULT TO IDENTIFY AXIAL SPONDYLOARTHRITIS IN WOMEN AND YOUNG PEOPLE. RESULTS FROM THE SPANISH ATLAS}

M. Garrido-Cumbrera ${ }^{1}$, V. Navarro-Compán ${ }^{2}$, J. Gratacos-Masmitja ${ }^{3}$, P. ZarcoMontejo $^{4}$, J. Correa-Fernández ${ }^{1}$, C. Sastré ${ }^{5}$, P. Plazuelo-Ramos ${ }^{6}$, E. CollantesEstevez ${ }^{7}$ on behalf of Atlas working group. ${ }^{1}$ Universidad de Sevilla, Health \& Territory Research (HTR), Seville, Spain; ${ }^{2}$ Hospital Universitario La Paz, IdiPaz, Madrid, Spain; ${ }^{3}$ Hospital Universitaria Parc Taulí, Rheumatology Department, Barcelona, Spain; ${ }^{4}$ Hospital Universitario Fundación Alcorcón, Rheumatology Department, Madrid, Spain; ${ }^{5}$ Novartis Farmacéutica Spain, Immunology, Hepatology and Dermatology, Barcelona, Spain; ${ }^{6}$ Spanish Federation of Spondyloarthritis Associations (CEADE), Presidency, Madrid, Spain; ${ }^{7}$ Reina Sofia University Hospital, Rheumatology Department, Cordova, Spain

Background: Delayed diagnosis in axial spondyloarthritis (axSpA) in Spain seems to be influenced by the patient diagnostic pathway. In particular, not all patients are diagnosed by rheumatologists, the profession better suited to make an axSpA diagnosis.

Objectives: The aim of this study is to evaluate the differences between patients diagnosed by a rheumatologist and those diagnosed by other healthcare professionals (HCPs)

Methods: In 2016, a sample of 680 unselected patients with axSpA participated in the Atlas of Axial Spondyloarthritis in Spain, an online survey. The sample was divided into: 1) Patients diagnosed by rheumatologists and 2) Non-Rheumatologist diagnosis including general practitioner, orthopaedic specialist, and physiotherapist. The Mann-Whitney and Pearson's chi-square tests were used to assess possible differences between both groups in sociodemographic characteristics, employment, lifestyle, patient-reported outcomes, and comorbidities Univariate and multivariate binary logistic regression was used to analyse the possible factors associated with diagnosis by a non-Rheumatologist.

Results: A total of 522 axSpA patients participated in this study: the mean age was 45.3 years, $51.0 \%$ were female, $38.5 \%$ had a university degree, and $71.6 \%$ and were married. Prior to diagnosis, axSpA patients visited different HCPs such as a General Practitioner (GP) (88.5\%), orthopaedic specialists $(71.6 \%)$, rheumatologists $(71.0 \%)$, and physiotherapists $(46.9 \%)$. The greatest number of visits (mean median) were made to physiotherapists $(3.4,3)$, followed by orthopaedic specialists $(3.0,2)$, rheumatologists $(2.0,1)$ and GPs $(2.6,2)$. The majority $(81.4 \%)$ of patients were diagnosed by a rheumatologist, while $18.6 \%$ received their diagnosis from a non-rheumatologist ( $10.9 \%$ orthopaedic specialist, $7.3 \%$ general practitioner, and $0.4 \%$ physiotherapist). With respect to other specialists such as the GP, orthopaedic specialist or physiotherapist, patients diagnosed by the rheumatologist were younge ( 44.3 vs $49.5, p<0.001$ ), more frequently female $(54.8 \%$ vs $45.2 \%$ of male, $p<0.001)$, with worse mental health ( 5.9 vs $4.8, p=0.039$ ), who visited more professionals before being diagnosed ( 3.0 vs $2.5, p=0.001$ ), were more frequently smokers $(40.2 \%$ vs $26.0 \%, p=0.010)$ and used more biologicals $(45.9 \%$ vs $33.0 \%, p=0.021)$. In the multivariate binary logistic regression, the qualitative factors associated with diagnosis by non-rheumatologists are males $(\mathrm{OR}=1.80)$, and the quantitative factors associated with the diagnosis by non-rheumatologists are older age $(B=0.027$; Table 1$)$.

Table 1. Logistic regression to analyses factor associated with non-rheumatologist diagnosis $(\mathrm{N}=440)$

\begin{tabular}{|c|c|c|c|c|}
\hline & \multicolumn{2}{|c|}{$\begin{array}{l}\text { Univariate logistic } \\
\text { analysis* }\end{array}$} & \multicolumn{2}{|c|}{$\begin{array}{l}\text { Multivariate logistic } \\
\text { analysis }{ }^{\star}\end{array}$} \\
\hline & OR & $p$-value ${ }^{2}$ & OR & p-value ${ }^{2}$ \\
\hline \multicolumn{5}{|l|}{ Qualitative factors } \\
\hline Gender. Female ${ }^{1}$ & 2.354 & $<0.001$ & 1.797 & 0.030 \\
\hline Smoking. Yes & 0.523 & 0.010 & 0.611 & 0.095 \\
\hline Used of Biologics. Yes & 0.581 & 0.022 & 0.640 & 0.086 \\
\hline Quantitative factors & B & $p$-value ${ }^{3}$ & B & p-value ${ }^{3}$ \\
\hline Age, in years & 0.044 & $<0.001$ & 0.027 & 0.028 \\
\hline GHQ-12 (0-12) & $\begin{array}{l}-0.059 \\
-0.59\end{array}-10$ & 0.038 & 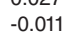 & 0.721 \\
\hline Number of HCPs seen before diagnosis & -0.294 & 0.001 & -0.153 & 0.151 \\
\hline
\end{tabular}

${ }^{*}$ Reference category of the dependent variable: Non-Rheumatologist; ${ }^{1}$ Female vs male ${ }^{2} \mathrm{p}$-value for test $\mathrm{H}_{0}: \mathrm{OR}=1{ }^{3} \mathrm{p}$-value for test $\mathrm{H}_{0}: \mathrm{B}=0$ 
Conclusion: One out of five patients with axSpA in Spain were not diagnosed by rheumatologists. Patients diagnosed by non-rheumatologists were more likely male and older, suggesting that the suspicion of axSpA in females and younger patients is low among these healthcare professionals. Beside the rheumatologist, it is essential to educate other HCPs on axSpA diagnostic criteria in order to facilitate correct referrals to rheumatologists and shorten the time to diagnosis and effective treatment. Acknowledgements: This study was supported by Novartis Spain. The authors would like to thank all patients who participated in the study

Disclosure of Interests: Marco Garrido-Cumbrera: None declared, Victoria Navarro-Compán Grant/research support from: Abbvie, BMS, Lilly, MSD, Novartis, Pfizer, Roche, and UCB, Jordi Gratacos-Masmitja Grant/research support from: Abbvie, BMS, Lilly, MSD, Novartis, Pfizer, Roche, and UCB, Pedro Zarco-Montejo: None declared, José Correa-Fernández: None declared, Carlos Sastré Employee of: Novartis Farmacéutica Spain, Pedro Plazuelo-Ramos: None declared, Eduardo Collantes-Estevez Grant/research support from:Abbvie, BMS, Lilly, MSD, Novartis, Pfizer, Roche, and UCB. DOI: 10.1136/annrheumdis-2021-eular.2551

\section{POS0995 EFFECT OF SEX IN CO-EXISTENT FIBROMYALGIA AND ENTHESITIS IN SPONDYLOARTHRITIS: ANCILLARY ANALYSIS OF THE ASAS-PERSPA STUDY}

G. Fitzgerald ${ }^{1}$, S. Maguire ${ }^{2,3}$, F. B. O'shea ${ }^{2,3}$, C. López-Medina ${ }^{4}$, M. Dougados ${ }^{4}$, N. Haroon ${ }^{5,6} .{ }^{1} \mathrm{Gal}$ way University Hospital, Rheumatology, Galway, Ireland; ${ }^{2}$ Trinity College Dublin, Medicine, Dublin, Ireland; ${ }^{3}$ St. James's Hospital, Rheumatology, Dublin, Ireland; ${ }^{4}$ Cochin Hospital, Rheumatology, Paris, France; ${ }^{5}$ University Health Network, Rheumatology, Toronto, Canada; ${ }^{6}$ Toronto Western Hospital, Rheumatology, Toronto, Canada

Background: Enthesitis is a common feature of axial spondyloarthropathy (axSpA) and psoriatic arthritis (PsA). Up to $25 \%$ of individuals with axSpA and PsA have a co-existing diagnosis of fibromyalgia syndrome (FMS). The anatomic overlap between tender points in FMS and sites of entheses is a challenge when differentiating between active SpA and FMS. Literature investigating the co-existence of enthesitis and FMS in individuals with $\mathrm{SpA}$ is sparse, in particular the effect of sex. The ASAS Peripheral involvement in Spondyloarthritis (PerSpA) study aims to characterize peripheral musculoskeletal in individuals with $\mathrm{SpA}$ across the world. Objectives: (1)To characterise the co-existence of enthesitis and FMS in individuals with $\mathrm{SpA}$.

(2)To explore the effect of sex on the presence of FMS and enthesitis.

Methods: All individuals from the cross-sectional multinational ASAS-PerSpA study with a diagnosis of axSpA, peripheral $\mathrm{SpA}(\mathrm{pSpA})$ or PsA according to their rheumatologist were included. The Fibromyalgia Rapid Screening Tool (FiRST) was used to make the diagnosis of FMS. The baseline descriptive and clinical differences between sexes were performed using T-tests and crosstabs. Sex-stratified comparisons within the following categories were conducted using chi-square analysis and ANOVA as appropriate: (1) enthesitis \& fibromyalgia; (2) enthesitis only; (3) fibromyalgia only; (4) neither.

Results: Baseline characteristics of the 4465 included patients are outlined in Table 1, stratified by sex. Enthesitis occurred in $44 \%(n=1984)$ of the population and was more common in females than males ( $48 \%$ vs $42 \%, p<0.01$ ). The majority affected had intermittent episodes of enthesitis (55\%, $n=1088)$, with the Achilles tendon and plantar fascia the two most common sites in both sexes. Enthesitis was more often confirmed on imaging in females than males ( $44 \%$ v $35 \%, p<0.01)$. The most common treatment for enthesitis was non-steroidal anti-inflammatories (97\%, $n=1318)$, with no difference when stratified by sex. FMS occurred in $19 \%(n=775)$ of patients and was more common in females than males ( $28 \%$ vs $13 \%, p<0.01$ ).

Table 1. Participant characteristics, stratified by sex. Values are mean (SD), median $\left(25^{\text {th }}, 75^{\text {th }}\right)$ or $n(\%)$. P-values are independent T-tests or Mann-Whitney as appropriate.

\begin{tabular}{lllll}
\hline Variable & Total & Male & Female & P value \\
\hline $\mathrm{N}$ & 4465 & 2724 & 1741 & \\
Age, years & $45(14)$ & $43(14)$ & $46(13)$ & $<0.01$ \\
Disease duration, years & $11(6,20)$ & $12(6,21)$ & $11(5,19)$ & 0.01 \\
Delay to diagnosis, years & $3(1,9)$ & $3(1,9)$ & $3(1,10)$ & 0.11 \\
HLA-B27 positive & $2066(66)$ & $1457(73)$ & $609(54)$ & $<0.01$ \\
Radiographic sacroiliitis & $2517(61)$ & $1788(70)$ & $729(46)$ & $<0.01$ \\
Sacroiliitis on MRI & $1817(65)$ & $1128(68)$ & $689(60)$ & $<0.01$ \\
axSpA ASAS criteria & $2910(65)$ & $1953(72)$ & $957(55)$ & $<0.01$ \\
pSpA ASAS criteria & $555(12)$ & $250(9)$ & $305(18)$ & $<0.01$ \\
CASPAR criteria & $1043(23)$ & $508(19)$ & $535(31)$ & $<0.01$ \\
BMI, kg/m ${ }^{2}$ & $26(23,29)$ & $26(23,29)$ & $26(23,30)$ & 0.24 \\
Axial involvement & $3428(76.8)$ & $2243(82.3)$ & $1185(68.1)$ & $<0.01$ \\
Peripheral involvement & $2541(56.9)$ & $1404(51.5)$ & $1137(65.3)$ & $<0.01$ \\
Enthesitis & $1984(44.4)$ & $1149(42.2)$ & $835(48.0)$ & $<0.01$ \\
Uveitis & $738(17)$ & $482(18)$ & $256(15)$ & 0.01 \\
Psoriasis & $1212(27)$ & $615(23)$ & $597(34)$ & $<0.01$ \\
Inflammatory bowel disease & $275(6)$ & $150(6)$ & $125(7)$ & 0.02 \\
\hline
\end{tabular}

Enthesitis and FMS occurred together in $10 \%$ of the cohort, was more common in women than men (see Figure 1) and was associated with a significantly $(p<0.01)$ longer delay to diagnosis of 1.8 years and a higher BMI of $2.1 \mathrm{~kg} / \mathrm{m}^{2}$ than people with enthesitis only. Objective confirmation of enthesitis was similar in those with and without FMS (38\% vs $38 \%, p=0.92)$

The presence of FMS added to the burden of disease in those with enthesitis as assessed by BASDAI (6.4 vs 3.6, $p<0.01$ ) and ASDAS-CRP ( 3.5 vs $2.5, p<0.01$ ) with no difference between sexes ( $p>0.05$ ).

Conclusion: In this large cross-sectional multinational analysis, FMS affected $19 \%$ of individuals with SpA. The co-existence of enthesitis and FMS occurred in $16 \%$ of females compared to $6 \%$ of males. The presence of FMS increased the burden of disease in those with enthesitis, as assessed by BASDAI and ASDASCRP, with no difference between men and women.

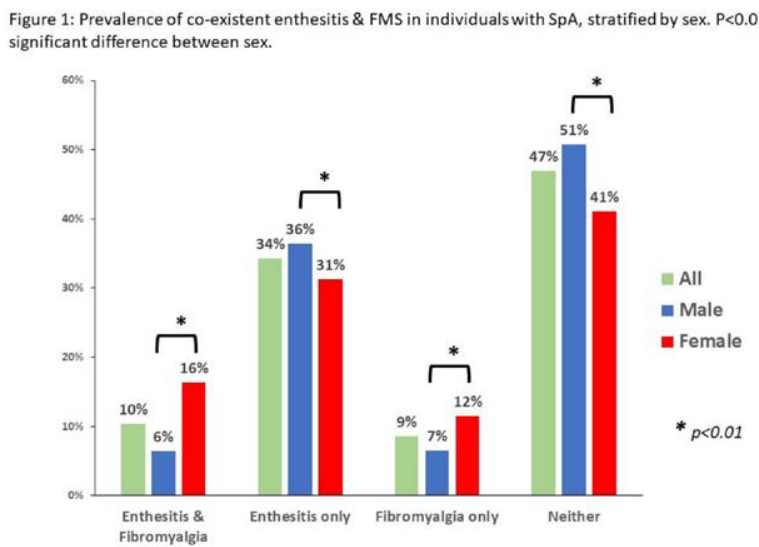

Disclosure of Interests: Gillian Fitzgerald: None declared, Sinead Maguire Grant/research support from: Recipient of Gilead Inflammation Fellowship, Finbar Barry O'Shea: None declared, Clementina López-Medina: None declared, Maxime Dougados: None declared, Nigil Haroon Speakers bureau: Received honorarium from AbbVie, Eli Lilly, Jannsen, Novartis, UCB, Consultant of: AbbVie, Eli Lilly, Jannsen, Novartis, UCB, Grant/research support from: AbbVie, Eli Lilly, Jannsen, Novartis, UCB.

DOI: 10.1136/annrheumdis-2021-eular.2556

\begin{tabular}{|l|l|}
\hline POS0996 & SIX-YEAR RESULTS FROM THE ESPERANZA \\
COHORT: EVALUATION OF CLINICAL FEATURES, \\
DISEASE ACTIVITY MEASURES AND TREATMENT \\
ASPECTS IN AXIAL AND PERIPHERAL EARLY \\
SPONDYLOARTHRITIS
\end{tabular}

C. Tornero $^{1}$, V. Navarro-Compán ${ }^{1}$, B. Joven-lbáñez ${ }^{2}$, R. Almodovar ${ }^{3}$, X. JuanolaRoura $^{4}$, C. Fernández-Carballido ${ }^{5}$, J. C. Quevedo-Abeledo ${ }^{6}$, J. Rosas ${ }^{7}$, A. Hernández ${ }^{8}$, C. A. Montilla-Morales ${ }^{9}$, J. R. Maneiro ${ }^{10}$, A. Juan-Mas ${ }^{11}$, J. A. Pinto Tasende ${ }^{12}$, M. Moreno ${ }^{13}$, J. Sanz ${ }^{14}$, T. Ruiz Jimeno $^{15}$, M. Moreno $^{16}$, M. L. Ladehesa Pineda ${ }^{17}$, E. De Miguel ${ }^{18}$ on behalf of Esperanza study group. ${ }^{1}$ Hospital Universitario La Paz., Department of Rheumatology., Madrid, Spain; ${ }^{2}$ Hospital Universitario 12 de Octubre, Department of Rheumatology, Madrid, Spain; ${ }^{3}$ Hospital Universitario Fundación Alcorcón, Department of Rheumatology, Madrid, Spain; ${ }^{4}$ Hospital Universitari de Bellvitge, Department of Rheumatology, Barcelona, Spain; ${ }^{5}$ Hospital General Universitario de Elda, Department of Rheumatology, Alicante, Spain; ${ }^{6}$ Hospital Universitario de Gran Canaria Doctor Negrín, Department of Rheumatology, Las Palmas de Gran Canaria, Spain; ${ }^{7}$ Hospital Marina Baixa, Department of Rheumatology, Alicante, Spain; ${ }^{8}$ Hospital Virgen de la Salud, Department of Rheumatology, Toledo, Spain; ${ }^{9}$ Hospital Universitario de Salamanca, Department of Rheumatology, Salamanca, Spain; ${ }^{10}$ Complejo Hospitalario Universitario de Santiago de Compostela, Department of Rheumatology, Santiago de Compostela, Spain; ${ }^{11}$ Hospital Universitario Son Llàtzer, Department of Rheumatology, Palma de Mallorca, Spain; ${ }^{12}$ Complejo Hospitalario Universitario de A Coruña, Department of Rheumatology, La Coruña, Spain; ${ }^{13}$ Hospital Parc Tauli, Department of Rheumatoloy, Barcelona, Spain; ${ }^{14}$ Hospital Universitario Puerta de Hierro, Department of Rheumatology, Madrid, Spain; ${ }^{15}$ Hospital de Sierrallana, Rheumatology, Torrelavega, Spain; ${ }^{16}$ Hospital Clínico Universitario Virgen de la Arrixaca, Department of Rheumatology, Murcia, Spain; ${ }^{17} \mathrm{Hospital}$ Universitario Reina Sofía, Department of Rheumatology, Córdoba, Spain;

${ }^{18}$ Hospital Universitario La Paz, Department of Rheumatology, Madrid, Spain

Background: Esperanza was a multicenter national health program developed to facilitate an early diagnosis of patients with Spondyloarthritis (SpA) in Spain. 